\title{
Short communication: Analysis of health and survival in a population of Ontario Holstein heifer calves
}

\author{
C. E. McCorquodale, ${ }^{*}$ A. Sewalem, $\nmid \ddagger^{1}$ F. Miglior, $\downarrow \ddagger$ D. Kelton, ${ }^{*}$ A. Robinson, $\S$ A. Koeck,§ and K. E. Leslie* \\ *Department of Population Medicine, University of Guelph, Guelph, Ontario, N1G 2W1, Canada \\ †Guelph Food Research Centre, Agriculture and Agri-Food Canada, Guelph, Ontario, N1G 5C9, Canada \\ ¥Canadian Dairy Network, Guelph, Ontario, N1K 1E5, Canada \\ §Department of Animal and Poultry Science, University of Guelph, Guelph, Ontario, N1G 2W1, Canada
}

\begin{abstract}
The objective of the present study was to investigate health and survival in heifer calves, from 16 farms in southwestern Ontario. Research technicians visited the farms on a weekly schedule for $16 \mathrm{mo}$, starting in January 2008, and collected blood samples and various measurements to determine the overall health status of the calves. Data of 1,588 Holstein heifer calves from birth until 90 to $120 \mathrm{~d}$ of age were analyzed. Initially, a survival analysis was carried out to determine which factors surrounding birth increased a calf's risk of mortality. The factors examined were type of birth, calving ease, season of birth, serum total protein, weight during first week of life, treatment status during first week of life, total number of treatments, and bovine respiratory disease status. In general, calves born in fall (OctoberDecember), low serum total protein, low weight, and calves treated for illness during the first week of life, increasing number of treatments, and being treated for bovine respiratory disease all increased a calf's risk of mortality. Genetic parameters for requiring treatment for illness, survival, bovine respiratory disease, other diseases, height, and weight were estimated. Heritabilities for treatment, survival, and diseases were low, ranging from 0.04 to 0.07 , and were not significant. Moderate and significant heritabilities were found for height (0.33 to 0.45$)$ and weight (0.24 to 0.44$)$. Treatment and survival to 90 to $120 \mathrm{~d}$ of age were favorably correlated, indicating that calves requiring less treatment have a higher survival rate and vice versa. Further, body weight was found to have a tendency of favorable genetic correlation $(-0.22$ to -0.53$)$ with treatment for diseases, indicating that calves with higher body weight in their first month of life were genetically more resistant to diseases than those with average body weight. Overall, our results show the potential of using data on calfhood disease and survival in future
\end{abstract}

Received May 15, 2012.

Accepted November 5, 2012.

${ }^{1}$ Corresponding author: Asheber.Sewalem@agr.gc.ca dairy cattle breeding programs. Further investigation and improved data collection are required to determine the full impact of genetics on health and survival in dairy heifer calves.

Key words: calfhood disease, survival, treatment, relative risk

\section{Short Communication}

Calfhood disease and survival have severe economic consequences for dairy producers. Estimates of all expenses associated with rearing replacement heifers range from 15 to $20 \%$ of total milk production costs (Heinrichs, 1993). The return on this investment is not fully realized until at least the end of the first lactation (Bach, 2011), making it economically important that heifer calves reach maturity and enter the milking herd.

Calf mortality rates vary across countries and dairy cattle populations. Gulliksen et al. (2009) reported a mortality rate of $3.3 \%$ in the first 6 mo of life in Norwegian Red calves. In southwestern Swedish farms, Svensson et al. (2006) found that $4 \%$ of calves died before the age of $210 \mathrm{~d}$, and Fuerst-Waltl and Sørensen (2010) observed that $3.2 \%$ of calves died within the first month of life in Danish Holstein heifer calves. In the United States, mortality rates of 7.8 and $1.8 \%$ of preweaned and weaned heifers, respectively, have been reported (US Department of Agriculture, 2010).

The 2 most frequent diseases affecting calves are diarrhea and respiratory disease. In the United States, scours, diarrhea, and other digestive problems are responsible for $57 \%$ of preweaned heifer deaths, followed by respiratory problems $(23 \%)$. For weaned heifers, respiratory disease was the single largest cause, accounting for $47 \%$ of the deaths (US Department of Agriculture, 2010). Previous studies showed that calfhood disease and mortality have a genetic component (Heringstad et al., 2008; Fuerst-Waltl and Sørensen, 2010; Henderson et al., 2011a,b). Although genetic selection for disease resistance, as well as improved perinatal and postnatal survival, could reduce the incidence of disease and overall calf mortality, these traits are generally neglected in 
Table 1. Standardized case definitions of diseases

\begin{tabular}{ll}
\hline Disease event & Definition \\
\hline Bovine respiratory disease & $\begin{array}{l}\text { Increased resting respiratory rate, sound, or effort and fever }\left[>39.5^{\circ} \mathrm{C}\left(>103^{\circ} \mathrm{F}\right)\right] \text { with one or more additional } \\
\text { signs such as coughing, nasal discharge, depression, decreased appetite, or rough hair coat }\end{array}$ \\
$\begin{array}{l}\text { Other } \\
\text { Diarrhea/scours }\end{array}$ & Warm is of looser consistency than normal for $\geq 2 \mathrm{~d}$ \\
Navel illness & Swelling of one or more joints resulting in lameness \pm fever \\
Joint illness & Depression \pm decreased appetite \pm fever of unknown origin \\
Dullness & Distension of the abdomen resulting in discomfort \pm respiratory distress \\
Bloat & Drooping of one or both ears \pm head-tilt \pm dullness \\
Otitis media & Traumatic injury, birth defect, ringworm, warts, and so on \\
Less frequent events &
\end{tabular}

dairy cattle breeding programs. The only trait related to calf survival and health that is routinely evaluated and included in selection indices is stillbirth (Interbull, 2012).

The objectives of this study were (1) to determine which factors surrounding birth increase a calf's risk of mortality using survival analysis, and (2) to estimate genetic parameters for health, weight, height, and survival traits.

Data were obtained from 16 farms in southwestern Ontario enrolled in the study from January through December 2008. Stillborn calves and calves that died within the first $24 \mathrm{~h}$ after birth were excluded from analyses. Research technicians visited the farms weekly for 16 mo starting in January 2008. The technicians collected blood samples and took various measurements to determine the overall health status of a calf, as each calf reached the appropriate ages. Calves were measured at 4 time points throughout the study: the initial assessment occurred at 0 to $8 \mathrm{~d}$ of age (T1), with the 3 follow-up assessments occurring at 14 to $22 \mathrm{~d}$ of age (T2), 35 to $43 \mathrm{~d}$ of age (T3), and 90 to $120 \mathrm{~d}$ of age (T4). Height, BW, and body temperature were measured and a health score was assigned at each assessment. Height was measured at the withers with the head in a neutral position. Body weight was measured using a heart-girth measuring tape pulled snugly around the thorax, just caudal to the forelimb.

A blood sample was obtained from each calf during the initial assessment. A $10-\mathrm{mL}$ sample was collected by jugular venipuncture using a 20-gauge, 1-inch hypodermic needle (BD Vacutainer Precision Glide, Becton, Dickinson and Co., Franklin Lakes, NJ), in a sterile, glass, serum Vacutainer without anticoagulant (BD Vacutainer, Becton, Dickinson and Co.). Samples were stored in coolers containing ice packs for transportation to the laboratory. Within $24 \mathrm{~h}$ of collection, the serum was separated by centrifugation at $970 \times g$ for 10 min at $\sim 20^{\circ} \mathrm{C}$. These samples were used to assess serum total protein (STP) using digital refractometry (model 300027, Sper Scientific Ltd., Scottsdale, AZ).
One-milliliter aliquots of serum were stored at $-20^{\circ} \mathrm{C}$ for further analysis.

Producers were provided with case definitions of 7 diseases (Table 1). For every occurrence of a health problem and treatment administered to a calf, the producer was requested to record the date, suspected disease, rectal temperature of the calf, and type of treatment given. To be considered a treatment or morbidity event, the treatment must have been given because of suspected illness, not as a preventative measure. Treatments with a long-acting antibiotic had to be more than $7 \mathrm{~d}$ apart to be considered as new treatment events. For any other medications, treatments had to be more than $3 \mathrm{~d}$ apart to be considered as separate treatments.

Information from herds that did not register calves in the official Holstein Canada herdbook or were not enrolled in CanWest DHI's milk recording program was acquired from producer records. Any calves with unknown or non-Holstein sires were removed from the database. Calves with non-Holstein maternal grandsires were also removed. After data cleaning, 1,588 calves sired by 252 bulls remained in the database. Enrollment on individual farms ranged from 9 to 428 calves.

Length of survival time, $t$, was defined as time (days) from birth to death, and the record was censored if the calf reached the final assessment of the study between 90 and $120 \mathrm{~d}$ of age (T4). A record was considered completed (uncensored) if the calf received a termination code, indicating that she was either culled or died for any reason.

Treatments given to the calf at various ages were defined as a binary traits $(0=$ no treatment given, $1=$ at least one treatment has been given) based on whether or not the calf had at least one treatment within 0 to $8 \mathrm{~d}$ of age (Trt1) or 14 to $22 \mathrm{~d}$ of age (Trt2), respectively. Bovine respiratory disease and other diseases were coded as binary traits $(0=$ no case, $1=$ at least one case) based on whether or not the calf had at least one case of the respective disease. The frequency of the other diseases was too low to estimate genetic parameters for each single trait. Survival was 
defined as a binary trait $(0=$ dead, $1=$ alive $)$, based on whether or not the calf was still alive at 90 to $120 \mathrm{~d}$ of age. Calf weight and height were analyzed at T1, T2, T3, and T4. To assess the effect of each covariate on calf survival, the Weibull proportional hazards model was used:

$$
\lambda(t)=\lambda_{0, \mathrm{~s}}(t) \exp \left[\mathbf{x}_{\mathbf{m}}^{\prime}(t) \boldsymbol{\beta}+\mathbf{z}_{\mathbf{m}}^{\prime} \mathbf{u}\right],
$$

where $\lambda(t)$ is the hazard function for calf survival; that is, the probability of dying at time $t$ given that the calf survived just before $t ; \lambda_{0, \mathrm{~s}}(t)=\lambda \rho(\lambda t)^{\rho-1}$ is the Weibull baseline hazard function with scale parameter $\lambda$ and shape parameter $\rho$, subscript $\mathrm{s}=$ lactation, and $t=$ time from birth until death or censoring; $\boldsymbol{\beta}$ contains covariates affecting the hazard, with $\mathbf{x}_{\mathbf{m}}^{\prime}(t)$ being the corresponding design vectors ( $\mathrm{m}$ is the number of independent covariates) and $\mathbf{u}$ the vector of random variables with associated incidence vector $\mathbf{z}_{\mathbf{m}}^{\prime}$. The fixed effects in the model included type of birth $(0=$ single birth, 1 = multiple birth), calving ease score ( 0 $=$ no assistance, $1=$ assisted), season of birth (winter $=$ January-March, spring = April-June, summer = July-September, fall $=$ October-December), STP score $(1=\leq 5.0 \mathrm{~g} / \mathrm{dL}, 2=5.1-6.0 \mathrm{~g} / \mathrm{dL}, 3=6.1-7.0 \mathrm{~g} / \mathrm{dL}$, $4=>7.0 \mathrm{~g} / \mathrm{dL})$, weight group at 0 to $8 \mathrm{~d}$ of age $(1=$ $\leq 37 \mathrm{~kg}, 2=>37-39 \mathrm{~kg}, 3=>39-44 \mathrm{~kg}, 4=>44-49$ $\mathrm{kg}, 5=>49 \mathrm{~kg})$, treatment at 0 to $8 \mathrm{~d}$ of age $(0=$ no treatment; $1=$ at least one treatment), total number of treatments $(0=$ no treatment, $1=$ treated once, 2 $=$ treated twice, $\geq 3=$ treated 3 or more times $)$, and bovine respiratory disease $(0=$ no case, $1=$ at least one case). The random effects included the effect of herd, assumed to follow a log gamma distribution, and the additive genetic effect of the sire of the calf, which was assumed to follow a multivariate normal distribution. With a total of 252 sires for 1,588 calves, there were not enough calves per sire to accurately predict the genetic effect of the sire. Therefore, a sire variance of 0.098 (Henderson et al., 2011a) was used in the analyses. Survival analysis was carried out using the Survival Kit version 5.1 (Ducrocq and Sölkner, 1998).

To estimate the genetic parameters for calf health traits, BW, height, and survival, linear animal models were used. First, a univariate analysis was run for Trt1, Trt2, bovine respiratory disease, and other diseases at times T1 and T2. For these traits, the number of records at T3 and T4 was insufficient to estimate genetic parameters. However, calf $\mathrm{BW}$ and height measured at T1, T2, T3 and T4 were analyzed. Subsequently, bivariate linear models were run between (a) Trt1, and Trt2 with survival at T4, and (b) Trt1 and Trt2 with weight at $\mathrm{T} 1$ and $\mathrm{T} 2$.
The following linear animal model was applied to all traits:

$$
\mathbf{y}=\mathbf{X} \mathbf{b}+\mathbf{Z a}+\mathbf{e}
$$

where $\mathbf{y}$ is a vector of observations for the analyzed trait; $\mathbf{b}$ is a vector of systematic effects, including fixed effects of herd, season of birth, type of birth, calving ease score, fixed regression of total volume of colostrum fed in the first $24 \mathrm{~h}$, and fixed regression of STP; $\mathbf{a}$ is a vector of random animal effects; $\mathbf{e}$ is a vector of random error; and $\mathbf{X}$ and $\mathbf{Z}$ are the corresponding incidence matrices. Description of fixed effects is the same as previously described. For health and survival traits, the weight group at 0 to $8 \mathrm{~d}$ of age was included as a fixed effect. The pedigree file was generated by tracing the pedigrees of calves with data 14 generations back and contained the relationship of 35,568 animals. (Co)variance components were estimated using the expectation maximization-REML procedure in the DMU package (Madsen and Jensen, 2008).

Mortality rates ranged from 0.0 to $11.0 \%$, with an overall calf mortality of $4.6 \%$. In total, $35 \%$ of calves required treatment for illness at least once during the study period; $13.4 \%$ of calves were treated during the first week of life and a further $12.7 \%$ of calves required treatment between 14 and $22 \mathrm{~d}$ of age. Bovine respiratory disease was the most commonly treated disease with a frequency of $9.5 \%$. Other diseases had a frequency of $4.1 \%$.

Season of birth was an important factor in determining the risk of mortality. Calves born in October through December were 1.9 times more likely to die than calves born in July through September (Figure 1a). Calves born during the spring (April-June) had the lowest risk of mortality compared with calves born during other seasons. For instance, spring-born calves were 3.2 and 6.1 times more likely to survive compared with calves born in summer and fall, respectively. Conflicting results have been reported on the effect of season of birth on calf mortality. Henderson et al. (2011a) reported that risk of mortality was largely constant across seasons of birth; however, a slightly lower mortality rate was found for calves born in the spring. Both Gulliksen et al. (2009) and Svensson et al. (2006) found that mortality rates increased during the colder months of the year in studies in Scandinavia. Gulliksen et al. (2009) reported that Norwegian cows produce lower quality colostrum during the winter months, perhaps explaining the increased mortality in the winter months. The pasture-based system of dairy production in Norway may account for the reported differences in colostrum quality and is not generally applicable to North Ameri- 
can calves. The increased mortality risk in calves born between October and December in the current study may be the result of exposure to increased precipitation and extreme temperature fluctuations, which make them more susceptible to bovine respiratory disease (Waltner-Toews et al., 1986a). It is important to note that the season of birth effect may be specific to the current study only. Data were collected for 1 yr only, not allowing us to study the influence of variations in precipitation and temperatures across years.

Colostrum management has long been associated with calf survival. Calves require colostrum to absorb immunoglobulins to protect against pathogens until their own immune system is developed (Godden,
2008). Serum total protein is an indirect measure of the level of immunoglobulins in the blood (Calloway et al., 2002). Serum total protein was an important factor in a calf's risk of mortality. It has been reported previously that calves with failure of passive transfer of immunoglobulins are at increased risk of mortality. Donovan et al. (1998) found that calves with an STP concentration of $<5.0 \mathrm{~g} / \mathrm{dL}$ were 3 to 6 times more likely to die than calves with an STP concentration of $>6.0 \mathrm{~g} / \mathrm{dL}$. A recent study by Henderson et al. (2011a) found that calves with an STP concentration of $<6.0$ $\mathrm{g} / \mathrm{dL}$ were more likely to die. These findings were corroborated in the current study, in which calves with an $\mathrm{STP}<5.0 \mathrm{~g} / \mathrm{dL}$ were 2.4 times more likely to die than

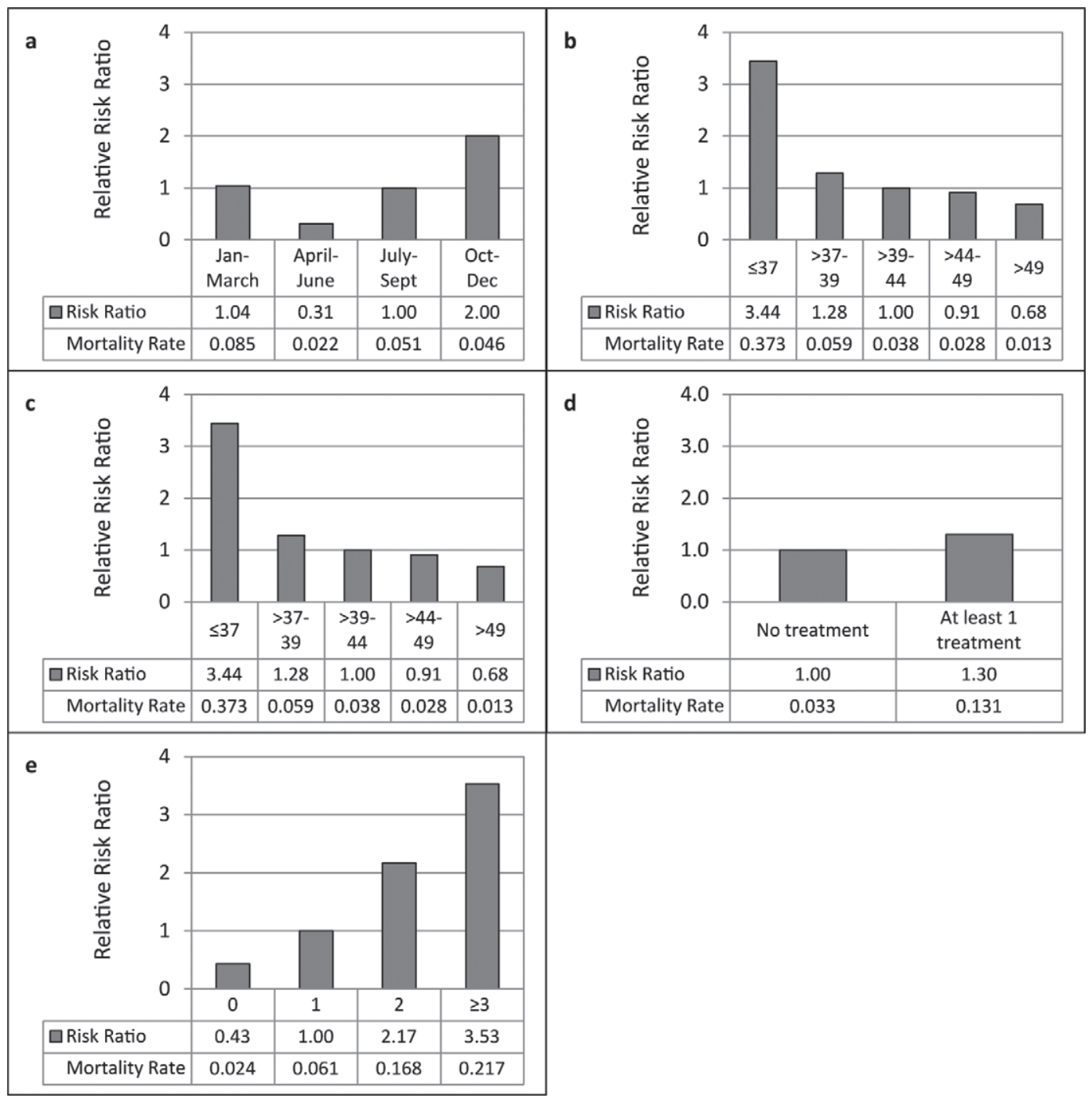

Figure 1. Relative risk ratios of mortality for (a) season of birth; calves born between July and September was set to 1; (b) serum total protein $(\mathrm{g} / \mathrm{dL})$; protein group between 5.1 and 6.0 was set to 1 ; (c) weight at 0 to $8 \mathrm{~d}$ of age $(\mathrm{kg})$; weight group between 39 and 44 was set to 1 ; (d) treated during first week of age; and (e) number of treatments; calves receiving 1 treatment was set to 1 as a reference group. 
calves with a concentration between 5.0 and $6.0 \mathrm{~g} / \mathrm{dL}$. A concentration of $>7.0 \mathrm{~g} / \mathrm{dL}$ appeared to provide a protective effect against mortality (Figure 1b).

Weight at 0 to $8 \mathrm{~d}$ of age had a significant $(P<0.05)$ effect on a calf's risk of mortality. Low BW were associated with higher calf mortality (Figure 1c). Calves weighing $\leq 39 \mathrm{~kg}$ were at an increased risk of mortality, whereas calves with $\mathrm{BW}>44 \mathrm{~kg}$ were at a decreased risk of mortality. This is contrast to a study completed on calves in New York State, where an optimum birth weight was observed (Henderson et al., 2011a). Those authors also found that calves weighing 38 to $41 \mathrm{~kg}$ were more likely to survive than calves in lighter or heavier weight groups. Heavier calves were found to be at the greatest risk, perhaps because of increased difficulties at birth (Linden et al., 2009). In the current study, both the 44-49 $\mathrm{kg}$ and $>49 \mathrm{~kg}$ weight groups had very low mortality rates, of 2.8 and $1.3 \%$, respectively, which may indicate that heavier calves are better able to fight off disease. This ability to resist disease and continue to gain weight may increase a heifer's chances of surviving.

Calves treated during the first week of life had a relative risk of mortality 1.3 times greater than calves that were not treated (Figure 1d), indicating that calves treated during the first week of life may be more susceptible to further disease and death. Treated calves were assumed to be sick, and illness has been shown to increase a calf's risk of mortality (Waltner-Toews et al., 1986b; Gulliksen et al., 2009). The number of treatments a calf received had the greatest influence on the risk of mortality. As the number of treatments increased, so did the risk of mortality. Calves that received 2 and at least 3 treatments were 2.17 and 3.53 times more likely, respectively, to die compared with calves that received only 1 treatment (Figure 1e). On the other hand, calves that did not receive any treatment were 2.3 times more likely to survive compared with the reference group. Henderson et al. (2011b) also found that a calf's risk of mortality increased with increasing number of treatments. Calves treated for bovine respiratory disease were at an increased risk of mortality (1.8 times) compared with calves that were not treated for bovine respiratory disease. Many previous studies have shown that bovine respiratory disease is responsible for calf mortality. Callan and Garry (2002) reported that bovine respiratory disease was responsible for $24.5 \%$ of preweaned calf deaths and $44.8 \%$ of calf losses after weaning. Gulliksen et al. (2009) found that Norwegian Red calves that had been treated for respiratory disease had an increased risk of mortality. In Swedish Red calves, pneumonia was the most common cause of death (Svensson et al., 2006). Calves with 4 or more cases of bovine respiratory disease were 1.9 times more unlikely to finish first lac- tation than those calves that did not experience bovine respiratory disease. Calves experiencing 1, 2, or 3 cases of bovine respiratory disease show a tendency toward decreased survival (Bach, 2011).

The present study showed that the type of birth did not significantly influence $(P>0.05)$ calf mortality. However, twin-born calves were 1.14 times more likely to die than singleton calves. Wells et al. (1996) reported that twin calves were 1.9 times more likely to die within the first $21 \mathrm{~d}$ of life than singleton calves. Gulliksen et al. (2009) found that twins and triplets were at an increased risk of death during the first week compared with singletons.

Type of calving (assisted vs. unassisted) did not significantly influence $(P>0.05)$ the risk of mortality. However, Gulliksen et al. (2009) and Henderson et al. (2011a) observed significant associations between calving difficulties and calf mortality. The small sample size and low mortality rate in the current study may explain why calving difficulty was not associated with an increased calf's risk of mortality.

Because of the small sample size in the current study, all estimated heritabilities had large standard errors (Table 2). Consequently, heritabilities for treatments, diseases, and survival were low and not significantly different from zero, whereas heritabilities for height and BW were moderate and significant. In a population of Holstein calves from New York State, Henderson et al. (2011b) estimated heritabilities (SE) of 0.10 (0.037) for bovine respiratory disease, $0.14(0.085)$ for umbilical diseases, and 0.04 (0.019) for bloat. In a study on respiratory disease in Norwegian Red calves, Heringstad et al. (2008) obtained a heritability of 0.05 using a threshold model. In the current study, the estimate of heritability of survival was 0.06. Henderson et al. (2011a) reported lower estimates, with the heritability of survival preweaning being close to zero (0.0006) and a heritability of survival postweaning of 0.04 . However, in the latter study, incentives were provided to the source farms for high serum total protein, and a substantial preventative treatment program was used at the heifer rearing facility, which probably resulted in a low mortality rate preweaning $(2.7 \%)$, affecting the heritability estimate. In Danish Holstein heifer calves, Fuerst-Waltl and Sørensen (2010) estimated heritabilities of 0.017 and 0.022 for calf mortality at 1 to $30 \mathrm{~d}$ of age and 31 to $180 \mathrm{~d}$ of age, respectively.

Height and weight were found to be moderately heritable traits. In a previous study on dairy calves by el Bushra et al. (1989), heritabilities of 0.50 and 0.53 were obtained for initial height at withers and initial weight, respectively.

The genetic correlations between Trt1 and Trt2 with survival at $\mathrm{T} 4$ were $-0.40 \pm 0.51$ and $-0.63 \pm$ 
Table 2. Heritabilities for treatment at T1 and T2; bovine respiratory disease, other diseases, survival; and height and BW at T1, T2, T3, and T4 analyzed using univariate linear animal models ${ }^{1}$

\begin{tabular}{lc}
\hline Trait & $\begin{array}{c}\text { Heritability } \\
( \pm \mathrm{SE})\end{array}$ \\
\hline Treatment at T1 & $0.07(0.06)$ \\
Treatment at T2 & $0.04(0.04)$ \\
Bovine respiratory disease & $0.04(0.05)$ \\
Other diseases & $0.07(0.05)$ \\
Survival & $0.06(0.05)$ \\
Height at T1 & $0.37(0.09)$ \\
Height at T2 & $0.37(0.09)$ \\
Height at T3 & $0.45(0.10)$ \\
Height at T4 & $0.33(0.10)$ \\
BW at T1 & $0.44(0.09)$ \\
BW at T2 & $0.37(0.09)$ \\
BW at T3 & $0.41(0.10)$ \\
BW at T4 & $0.24(0.09)$ \\
\hline
\end{tabular}

${ }^{1}$ T1: $0-8 \mathrm{~d}$ of age; T2: 14-22 d of age; T3: 35-43 d of age; T4: 90-120 d of age.

0.66, respectively. Although these correlations were not significant, they may indicate that calves genetically susceptible to requiring treatment are less likely to survive until 90 to $120 \mathrm{~d}$ of age. The genetic correlations between Trt1 and Trt2 with weight at T1 were $-0.22 \pm$ 0.37 and $-0.53 \pm 0.52$, respectively. The corresponding figures with weight at $\mathrm{T} 2$ were $-0.27 \pm 0.38$ and -0.51 \pm 0.57 . These negative genetic correlations show that calves that are more susceptible to requiring treatment have a lower weight. Two possible theories explain this finding. The first is that heavier calves are generally in better health and able to defend against disease, thus reducing their need for treatment. The second is that calves requiring treatment must spend more energy fighting off disease and are not able to maintain the same rate of gain as their healthy counterparts. The genetic correlation between weight at $\mathrm{T} 1$ and $\mathrm{T} 2$ was positive and strong $(0.82 \pm 0.07)$.

In conclusion, the present study showed the potential of using data on calfhood disease and survival in future dairy cattle breeding programs. Further investigation and improved data collection are required to determine the full impact of genetics on health and survival in dairy heifer calves.

\section{REFERENCES}

Bach, A. 2011. Associations between several aspects of heifer development and dairy cow survivability to second lactation. J. Dairy Sci. 94:1052-1057.
Callan, R. J., and F. B. Garry. 2002. Biosecurity and bovine respiratory disease. Vet. Clin. North Am. Food Anim. Pract. 18:57-77.

Calloway, C. D., J. W. Tyler, R. K. Tessman, D. Hostetler, and J. Holle. 2002. Comparison of refractometers and test endpoints in the measurement of serum protein concentration to assess passive transfer status in calves. J. Am. Vet. Med. Assoc. 221:1605-1608.

Donovan, G. A., I. R. Dohoo, D. M. Montgomery, and F. L. Bennett. 1998. Associations between passive immunity and morbidity and mortality in dairy heifers in Florida, USA. Prev. Vet. Med. $34: 31-46$

Ducrocq, V., and J. Sölkner. 1998. The survival kit, V5.1: A Fortran package for large analyses of survival data. Pages 447-450 in Proc. 6th World Congr. Genet. Appl. Livest. Prod., Armidale, Australia. University of New England, Armidale, NSW, Australia.

el Bushra, O. E., C. J. Wilcox, J. M. Wing, and R. C. Littell. 1989. Genetic effects of dairy calf growth. J. Dairy Sci. 72:162-166.

Fuerst-Waltl, B., and M. K. Sørensen. 2010. Genetic analysis of calf and heifer losses in Danish Holsteins. J. Dairy Sci. 93:5436-5442.

Godden, S. 2008. Colostrum management for dairy calves. Vet. Clin. North Am. Food Anim. Pract. 24:19-39.

Gulliksen, S. M., K. I. Lie, T. Løken, and O. Østerås. 2009. Calf mortality in Norwegian dairy herds. J. Dairy Sci. 92:2782-2795.

Heinrichs, A. J. 1993. Raising dairy replacements to meet the need of the 21st century. J. Dairy Sci. 76:3179-3187.

Henderson, L., F. Miglior, A. Sewalem, D. Kelton, A. Robinson, and K. E. Leslie. 2011a. Estimation of genetic parameters for measures of calf survival in a population of Holstein heifer calves from a heifer raising facility in New York State. J. Dairy Sci. 94:461-470.

Henderson, L., F. Miglior, A. Sewalem, J. Wormuth, D. Kelton, A. Robinson, and K. E. Leslie. 2011b. Short communication: Genetic parameters for measures of calf health in a population of dairy calves in New York State. J. Dairy Sci. 94:6181-6187.

Heringstad, B., Y. M. Chang, D. Gianola, and O. Østerås. 2008. Short communication: Genetic analysis of respiratory disease in Norwegian Red calves. J. Dairy Sci. 91:367-370.

Interbull. 2012. Description of national genetic evaluation systems for dairy cattle traits as applied in different Interbull member countries. Accessed Apr. 11, 2012. http://www-interbull.slu.se/national_ges_info2/framesida-ges.htm.

Linden, T. C., R. C. Bicalho, and D. V. Nydam. 2009. Calf birth weight and its association with calf and cow survivability, disease incidence, reproductive performance, and milk production. J. Dairy Sci. 92:2580-2588.

Madsen, P., and J. Jensen. 2008. A User's Guide to DMU: A Package for Analyzing Multivariate Mixed Models. Version 6, release 4.7. Danish Institute of Agricultural Sciences, Tjele, Denmark.

Svensson, C., A. Linder, and S.-O. Olsson. 2006. Mortality in Swedish dairy calves and replacement heifers. J. Dairy Sci. 89:4769-4777.

US Department of Agriculture. 2010. Dairy 2007-Heifer calf health and management practices on US dairy operations, 2007. USDA:APHIS:VS:CEAH. Fort Collins, CO.

Waltner-Toews, D., S. W. Martin, and A. H. Meek. 1986b. The effect of early calfhood health status on survivorship and age at first calving. Can. J. Vet. Res. 50:314-317.

Waltner-Toews, D., S. W. Martin, A. H. Meek, and I. McMillian. 1986a. Dairy calf management, morbidity and mortality in Ontario Holstein herds. II. Age and seasonal patterns. Prev. Vet. Med. $4: 125-135$.

Wells, S. J., D. A. Dargatz, and S. L. Ott. 1996. Factors associated with mortality to 21 days of life in dairy heifers in the United States. Prev. Vet. Med. 29:9-19. 